\title{
Currículo: lições do passado em tempos de BNCC
}

\author{
Curriculum: lessons from the past in BNCC times
}

\section{Currículo: lecciones del pasado en tiempos de BNCC}

\author{
Luciola Licinio Santos ${ }^{1}$
}

Universidade Federal de Minas Gerais, Faculdade de Educação, Professora. https://orcid.org/0000-0002-9816-2440

\section{Leandra de Oliveira ${ }^{2}$}

Escola do Legislativo - Assembleia Legislativa do Estado de Minas Gerais, Analista de Projetos Educacionais.

https://orcid.org/0000-0001-8178-7471

Resumo: Este artigo apresenta e discute uma pesquisa realizada em 2012 sobre a implementação de uma proposta curricular denominada Proposições Curriculares, na rede municipal de Belo Horizonte, e tem um duplo objetivo. 0 primeiro deles é compreender os fatores que levaram à proposta de um novo currículo, bem como a seu processo de elaboração e à sua implementação nas escolas. 0 outro objetivo é possibilitar uma reflexão sobre a Base Nacional Comum Curricular (BNCC) a partir dessa experiência do passado. A pesquisa se constituiu em um estudo de caso do tipo etnográfico, em que foi utilizada a observação participante, também a análise documental e a entrevista semiestruturada como instrumentos de coleta de dados que foram analisados com recursos da análise de conteúdo. A investigação foi realizada em uma escola na qual foram observadas as práticas das docentes e do grupo gestor, com entrevistas às professoras do ciclo de alfabetização. Baseando-se no ciclo de politicas de Ball e colaboradores, o trabalho mostra os contextos em que essa política curricular emergiu e se desenvolveu, com destaque para a realização prática do currículo. Analisa ainda as tensões e as formas de controle no processo de recontextualização do currículo escrito no cotidiano escolar. Finalmente, aponta as lições que podem ser tiradas dessa experiência para se pensar a BNCC, indicando problemas que um currículo nacional e as concepções que o fundamentam podem trazer para a prática docente e para a formação dos estudantes.

Palavras-chave: Currículo prescrito. Currículo em ação. Abordagem do ciclo de políticas. Implementação de currículos.

Abstract: This article focuses on a research carried out in 2012 on the implementation of a curricular proposal called Curricular Propositions, in Belo Horizonte municipal schools and has a double objective.

Pós-doutor e Doutora pelo Departamento de Sociologia do Instituto de Educação da Universidade de Londres.

Doutora em Educação pela Universidade Federal de Minas Gerais; Mestre e Especialista em Educação Tecnológica pelo Centro Federal de Educação Tecnológica de Minas Gerais. 
The first one is to understand the factors that led to the proposal of a new curriculum, as well as its elaboration process and its implementation in schools. The other objective is to enable a reflection on the National Curriculum Common Core (Base Nacional Comum Curricular - BNCC), based on this past experience. The research approach was an ethnographic case study in which participant observation was used, as well as documentary analysis and semi-structured interviews as data collection instruments, which were analyzed using content analysis resources. The investigation was carried out in a school where the practices of teachers and the management group were observed and teachers of the literacy cycle were interviewed. Based on the policy cycle approach formulated by Ball and collaborators, the work shows the contexts in which this curriculum policy emerged and developed, with emphasis on the practical realization of the curriculum. It also analyzes the tensions and forms of control in the process of recontextualizing the written curriculum in everyday school life. Finally, it points out the lessons that can be drawn from this experience to think about the BNCC, indicating problems that a national curriculum and the concepts that underlie it can bring to teaching practice and the students life.

Keywords: Prescribed curriculum. Curriculum in action. Policy cycle approach. Curriculum implementation.

Resumen: Este artículo presenta y discute una investigación realizada en 2012 sobre la implementación de una propuesta curricular, llamada Propuestas Curriculares, en la red municipal de Belo Horizonte y tiene un doble objetivo. El primero es comprender los factores que llevaron a la propuesta de un nuevo plan de estudios, así como su proceso de elaboración y su implementación en las escuelas. El otro objetivo es permitir una reflexión sobre la Base Curricular Común Nacional (BNCC), basada en esta experiencia pasada. La investigación consistió en un estudio de caso etnográfico, en el que se utilizó la observación participante, así como análisis de documentos y entrevistas semiestructuradas como instrumentos de recopilación de datos, que se analizaron con recursos de análisis de contenido. La investigación se llevó a cabo en una escuela donde se observaron las prácticas de los maestros, el grupo de gestión y se entrevistó a los maestros del ciclo de alfabetización. Basado en el ciclo de politicas de Ball y sus colaboradores, el trabajo muestra los contextos en los que surgió y se desarrolló esta política curricular, con énfasis en la realización práctica del plan de estudios. También analiza las tensiones y las formas de control en el proceso de recontextualización del currículo escrito en la vida escolar cotidiana. Finalmente, señala las lecciones que se pueden extraer de esta experiencia para pensar sobre BNCC, indicando los problemas que un curriculum nacional y sus conceptos subyacentes pueden aportar a la práctica docente y a la capacitación de los estudiantes.

Palabras clave: Currículum prescrito. Currículum en acción. Enfoque del ciclo de políticas. Implementación curricular.

Recebido em 14 de maio de 2020

Aceito em 15 de agosto de 2020

Publicado em 28 de setembro de 2020 


\section{INTRODUÇÃO}

Neste momento de implementação da Base Nacional Comum Curricular (BNCC), é importante uma reflexão, a partir de experiências concretas de reformas curriculares, que possibilitem descortinar alguns desdobramentos futuros que essas reformas podem ter quando postas em prática. Esse artigo volta-se para uma pesquisa realizada em 2012 sobre a implementação de uma proposta curricular, na rede municipal de Belo Horizonte, denominada Proposições Curriculares. Essa proposta foi justificada como uma forma de superar lacunas deixadas pela proposta anterior - Escola Plural.

Este trabalho tem um duplo objetivo. 0 primeiro deles é compreender os fatores que levaram à elaboração de um novo currículo para a rede municipal de Belo Horizonte, bem como o processo de elaboração desse currículo e sua implementação nas escolas. 0 outro objetivo é possibilitar uma reflexão sobre a BNCC a partir daquela experiência. Como surgiu e foi elaborada a proposta denominada Proposições Curriculares? Que tipos de dificuldades os professores tiveram para colocá-la em prática? Quais os mecanismos que os órgãos centrais utilizaram para implementá-la? Quais as críticas levantadas pelos professores? Que lições podem ser aprendidas com essa experiência?

0 artigo está dividido em cinco partes, sendo esta introdução a primeira delas. $\mathrm{Na}$ segunda e terceira partes do trabalho é apresentado o referencial teórico da pesquisa, seguido do percurso metodológico utilizado. Na quarta parte é analisado como surgiu e como foi elaborado o texto curricular, bem como sua aplicação na prática cotidiana das escolas, ou seja, o contexto de influência, o contexto da produção do texto curricular e o contexto da prática. Por último, são feitas algumas considerações à guisa de conclusões.

\section{PROPONDO E DESENUOLUENDO CURRÍCULOS}

Para fundamentar as discussões sobre a proposta curricular da rede municipal de Belo Horizonte serão aqui colocadas e debatidas questões sobre o currículo escrito e o currículo em ação, apontando as funções reguladoras do primeiro e os aspectos da prática e do cotidiano escolar que têm influência sobre o segundo. Será também apresentada a abordagem do ciclo de políticas, elaborada por Richard Bowe, Stephen Ball e Anne Gold, como referência teórico-analítica escolhida para se compreender o processo de elaboração da política curricular e as mudanças que ocorrem durante sua implementação nas instituições escolares. 


\subsection{CURRÍCULO PRESCRITO E CURRÍCULO EM AÇÃO}

Goodson (2011) define o currículo escrito como um testemunho visível, público e sujeito a mudanças; uma lógica que se escolhe para justificar determinadas intenções básicas de escolarização que, por meio da promulgação, serão operacionalizadas em estruturas e instituições. Os conflitos que surgem em torno da definição do currículo escrito são provas visíveis da luta constante que envolve as definições de objetivos e aspirações em torno da escolarização. Tais conflitos possuem um significado simbólico e um significado prático, já que as ações e aspirações presentes no currículo escrito tornam-se referenciais para avaliação e análise dos ideais postos para a educação em uma determinada época (GOODSON, 2011).

Para Sacristán (2000), o currículo prescrito é inerente aos sistemas educativos minimamente organizados, tendo em vista seu intuito de controlar a educação enquanto sistema ideológico. É um instrumento de regulações econômicas, políticas e administrativas, uma vez que traz implicações na ordenação do sistema educativo, na estrutura das instituições e na distribuição do professorado. Com esse instrumento, os sistemas de ensino delimitam conhecimentos, saberes a serem adquiridos pelos alunos, seus objetivos e suas intenções educativas e, muitas vezes, indicam as metodologias para se alcançar os objetivos que desejam (SACRISTÁN, 2000).

Para se elaborar um currículo é necessário decidir que tipos de experiências serão nele incluídas ou não. Definir quais conhecimentos, saberes e práticas farão parte do currículo implica processos de inclusão e exclusão social, os quais se constituem em decisões políticas. Partindo dessa premissa, a teoria crítica de currículo propõe a análise dos interesses subjacentes às propostas curriculares e sua vinculação com diferentes projetos de desenvolvimento sociocultural. As teorias pós-críticas buscam discutir questões de poder e de controle envolvidas nas relações de gênero, etnia/raça - implícitos e explícitos no currículo - e problematizam os significados construídos pelos currículos e suas relações com a subjetividade dos alunos e dos professores. Ambas as teorias nos ajudam "a compreender os processos pelos quais, através das relações de poder e controle, nos tornamos aquilo que somos." (SILVA, 2005, p. 147).

As discussões sobre o currículo escrito incluem defesa, críticas e questionamentos sobre os currículos locais e nacionais. Os primeiros são defendidos como uma forma de se elaborar currículos sintonizados com a cultura e as tradições locais e com a participação daqueles que irão desenvolvê-los. 0 currículo nacional foi objeto de críticas contundentes de acadêmicos norte-americanos e ingleses na década de 1980 e de brasileiros na década seguinte. Foi criticada a relação entre currículos nacionais e sistemas nacionais de avaliação que criam hierarquias e competição entre as escolas. Apple (2006) mostra que impor currículos nacionais, na tentativa de que todos os estudantes do país aprendam as mesmas 
coisas, é ignorar que tais currículos são interpretados a partir de leituras diferenciadas e implementados segundo as tradições e as possibilidades locais. Há ainda que se considerar que os currículos nacionais geralmente são elaborados por especialistas, com nenhuma ou pequena participação dos docentes que irão executá-lo.

Segundo Macedo (2006), a preocupação em distinguir o currículo formal (prescrito) do currículo em ação surge como forma de contraposição à noção burocratizada que teorias mais tradicionais do campo atribuíam ao currículo, ao focalizar seus estudos em documentos legais e políticas institucionais. A valorização das experiências dos educandos, de suas vivências no cotidiano escolar e o reconhecimento da comunidade escolar enquanto ativa e dinâmica põem em xeque a ideia de que o currículo prescrito é implementado no chão da escola. Nessa perspectiva, o currículo em ação é pensado considerando que professores e alunos não são consumidores passivos de prescrições e propostas curriculares. Esses atores agem e reagem sobre o currículo incorporando a ele novos significados, reconstruindo-o e concretizando-o em função de diferentes fatores - condicionantes sociais, estruturais e institucionais.

Quando uma proposta curricular adentra os muros da escola, não encontra ali um ambiente que aguarda ideias exteriores se apresentarem para dar um ordenamento a suas ações. Ao chegar, uma proposta curricular se depara com propostas anteriores e com a prática educativa já em movimento, sendo recontextualizada com base em experiências e vivências dos sujeitos que fazem parte do ambiente escolar. Entre esses sujeitos, a literatura destaca o professor como o principal agente no processo de reconstrução curricular. Todavia, nos processos de elaboração das propostas curriculares, o docente tem sido geralmente considerado um executor daquilo que os textos propõem, ao invés de um agente criativo, capaz de fazer parte da elaboração do currículo.

A implementação do currículo implica um processo de negociação de sentidos cujo resultado pode diferir completamente da proposta original, o que coloca o professor como um sujeito ativo na implementação curricular, e não apenas como receptor e executor passivo. Segundo Silva (2009), ao agirmos sobre os materiais recebidos, podemos desviá-los, refratálos, subvertê-los, parodiá-los, carnavalizá-los ou contestá-los, ações que variam de acordo com as épocas e situações. Ball, Maguire e Braun (2012) vão mais adiante ao argumentarem que não se deve usar o termo implementação, pois as políticas, quando colocadas em prática, são modificadas/transformadas de maneiras originais, ao envolverem processos criativos de interpretação e recontextualização, uma vez que os textos políticos são escritos em "relação à melhor de todas as escolas possíveis que só existe na imaginação" de quem os produz (BALL; MAGUIRE; BRAUN, 2012, p. 13-14).

Em síntese, o currículo em ação é forjado pela construção de valores, identidades e subjetividades, em um processo conflituoso e constantemente ressignificado pelo trabalho 
do professor. 0 currículo encontra no ambiente escolar múltiplos determinantes, relacionados às condições de trabalho, às concepções dos educadores, à organização da instituição escolar, ao perfil dos alunos, aos recursos físicos e materiais, às tradições pedagógicas, elementos que incidem sobre o currículo e com os quais o professor lida simultânea e cotidianamente.

\subsection{CICLO DE POLÍTICAS}

A abordagem do ciclo de políticas, proposta por Richard Bowe, Stephen Ball e Anne Gold, é o referencial teórico-analítico utilizado para discutir a elaboração da política curricular da rede municipal de Belo Horizonte e suas repercussões no trabalho das professoras. Segundo Mainardes (2006), o ciclo de políticas é uma abordagem que articula processos macro e micro de análise, ao tratar da natureza complexa e controversa da política educacional e da ação dos profissionais que lidam com ela no nível local.

0 ciclo de políticas foi constituído inicialmente por três contextos principais: contexto de influência, contexto da produção de texto e contexto da prática (BOWE; BALL; GOLD, 1992). Esses contextos são os referenciais que permitem discutir a relação entre currículo e trabalho do professor, articulando ambos à realidade global, nacional e local. Na abordagem do ciclo de políticas, é importante considerar de forma interdependente o processo de elaboração e implementação da política curricular.

0 contexto de influência é onde normalmente se inicia a política pública e onde são construídos os discursos políticos proferidos por diferentes grupos de interesses que lutam "[...] para influenciar a definição e os propósitos sociais da educação e do que significa ser educado." (BOWE; BALL; GOLD, 1992, p. 19, tradução nossa). As arenas de ação desse contexto abrangem as redes sociais, grupos políticos, o governo e o legislativo, onde são estabelecidos conceitos-chave que adquirem legitimidade e fornecem elementos para a iniciação da política. Esse contexto é marcado por influências globais, internacionais, nacionais e locais que, por sua vez, são sempre recontextualizadas e reinterpretadas nos micro-contextos.

0 contexto de produção do texto envolve o processo de elaboração dos textos políticos (regulamentações oficiais, propostas curriculares, comentários sobre as propostas, vídeos), que são articulados com a linguagem do interesse público. Os textos políticos apelam para alegações do senso comum e para razões políticas; são resultado de disputas e de acordos entre os grupos que competem para controlar a representação da política (BOWE; BALL; GOLD, 1992). 
Muitos textos são produzidos para clarear, explicar, reforçar a política oficial, o que não significa que sejam coerentes entre si. Bowe, Ball e Gold (1992) argumentam que os textos políticos representam idealizações do "mundo real" e não cobrem todas as eventualidades, devendo ser lidos em relação ao tempo, ao lugar de sua produção e em confronto com outros textos. Os textos políticos são produtos de negociações firmadas em vários estágios e contextos do processo de elaboração, ilustrando o esforço de seus autores pelo controle dos significados para garantir uma leitura "correta" da política (BALL, 1994). Em função disso, textos políticos não são necessariamente claros ou completos, pois são produtos de múltiplas influências e agendas.

Bowe, Ball e Gold (1992) apoiam suas análises sobre o texto político em dois estilos de textos propostos por Roland Barthes - o texto readerly (ou prescritivo) e o texto writerly. 0 primeiro oferece o mínimo de oportunidade para a interpretação criativa do leitor pressupondo que esse tem pouco a contribuir com o texto produzido. 0 texto writerly convida o leitor a cooperar, a interagir e a ser coautor instigando-o a colocar seus conhecimentos em confronto com o novo.

0 contexto da prática, para o qual a política está destinada, é aquele em que a política original é modificada e transformada. (BOWE; BALL; GOLD, 1992). Nesse cenário, o texto político não é simplesmente recebido e interpretado pelos sujeitos que nele atuam, mas é reinterpretado e recriado (BOWE; BALL; GOLD, 1992). Os sujeitos confrontam a política com suas histórias, experiências, valores e propósitos expressando diferentes interesses e compreensão em relação à política proposta. 0 contexto da prática evidencia que os autores não controlam os significados dos seus textos, uma vez que partes do texto serão rejeitadas, destacadas ou incompreendidas.

Ao aprofundar suas análises sobre o processo de elaboração de políticas, Ball (1994) acrescenta ao ciclo outros dois contextos: o contexto de resultados ou efeitos e o de estratégia política. Nesse artigo, como já foi dito, serão utilizados apenas os três primeiros aqui abordados.

\section{LOCAL DA PESQUISA E PERCURSOS METODOLÓGIICOS}

\subsection{A ESCOLA PESQUISADA}

A escola em que foi realizada a pesquisa, aqui denominada Escola Arco-íris, pertence à rede municipal de ensino de Belo Horizonte. 0 Sistema de Educação de Belo 
Horizonte oferece atendimento prioritário à Educação Infantil e ao Ensino Fundamental. A rede municipal possuía, em 2012, 169 escolas de Ensino Fundamental e 67 Unidades Municipais de Educação Infantil (UMEI), distribuídas em nove regionais administrativas. A Secretaria Municipal de Educação (SMED) é o órgão administrativo central do sistema de ensino municipal, mas conta com Gerências Administrativas em cada regional. Na ocasião da pesquisa, havia 121.584 alunos matriculados no Ensino Fundamental. A rede possuía em torno de 7.289 professores, sendo que 3.709 lecionavam no $1^{\circ}$ e no $2^{\circ}$ ciclo.

A Escola Arco-íris situa-se em um bairro relativamente tranquilo e é fruto da reivindicação da comunidade local, que se mobilizou para ver aprovado o projeto de sua construção no Orçamento Participativo. A escola possui uma estrutura física adequada, distribuída em prédios e áreas abertas. Além das salas de aula, a escola conta com biblioteca, laboratório, sala de vídeo, sala de informática, sala de multiuso, pátio coberto e pátio aberto, quadra de esportes, mobiliário e equipamentos em bom estado de conservação.

\subsection{COLETA E TRATAMENTO DOS DADOS}

Nesta pesquisa buscou-se superar as limitações identificadas por Lopes (2006) nas produções do campo do currículo, ainda que cientes de que outras limitações poderão estar presentes. Segundo Lopes (2006), essas limitações se referem ao estabelecimento de relações deterministas dos currículos com a prática pedagógica; à desconsideração do caráter produtivo das instâncias micro; à falta de associação analítica entre os elementos específicos com noções sociais mais amplas; à análise da escola ou sala de aula como uma unidade isolada, onde o currículo se desenvolve apenas em função das concepções dos sujeitos atuantes na prática.

A pesquisa configura-se como um estudo de caso do tipo etnográfico, por acompanhar in loco o trabalho de professoras do $1^{\circ}$ ciclo de formação humana, a fim de identificar as repercussões que as Proposições Curriculares trouxeram à sua atividade profissional. Segundo André (2005), no estudo de caso do tipo etnográfico o pesquisador necessita descentralizar-se de seu universo e colocar o eixo de referência no universo investigado (relativização), mas, ao mesmo tempo, deve distanciar-se da situação investigada para apreender as práticas e produções culturais do grupo estudado (estranhamento). Para isso, o pesquisador realiza a observação participante, que the possibilitará descrever densamente as estruturas complexas e percepções particulares dos atores (ANDRÉ, 2005).

Para escolha da instituição onde a investigação foi realizada, foram considerados aspectos geográficos relacionados à facilidade de acesso e determinadas especificidades 
pedagógicas, pois as informações que circulavam sobre as práticas educativas da escola também influenciaram a escolha. A instituição era conhecida na região por possuir um Projeto Político-Pedagógico diferenciado e pela construção coletiva e criativa de suas práticas educativas A decisão de investigar o $1^{\circ}$ ciclo (três primeiros anos do ensino fundamental) decorreu da importância desse ciclo no processo de escolarização.

Os sujeitos que compuseram essa pesquisa foram 13 professoras do $1^{\circ}$ ciclo, todas com graduação em Pedagogia, exceto uma delas, que tinha graduação em Letras, sendo que 7 fizeram ou estavam realizando curso de especialização. Também foram entrevistadas duas coordenadoras, uma diretora, uma vice-diretora e uma professora representante da Secretaria Municipal de Educação (SMED), que atuava como acompanhante pedagógica da escola. Esse grupo era bem heterogêneo quanto à faixa etária (entre 26 e 52 anos) e à experiência como docentes.

Após a concordância da escola em participar da pesquisa, foi feita uma reunião com as professoras, quando foram explicados os objetivos da investigação e os cuidados éticos que seriam tomados, razão pela qual os nomes dos participantes da pesquisa e da escola são fictícios. A pesquisa de campo foi realizada em duas fases. A primeira teve duração aproximada de 8 meses e foi realizada no período vespertino. Nessa fase foram contabilizadas 161 horas de observação, realizada em 61 dias alternados. Durante esse período foi observada a rotina da escola, a organização do turno, o dia-a-dia das professoras e dos alunos fora da sala de aula e as demandas de trabalho feitas pela coordenação e pela direção.

A segunda fase se consistiu em observações em salas de aula, nos meses de outubro, novembro e dezembro de 2012. Foi realizado o acompanhamento do trabalho em sala de aula das professoras do $1^{\circ}, 2^{\circ}$ e $3^{\circ}$ ano do $1^{\circ}$ ciclo (uma turma de cada ano do ciclo), escolhendo aquelas turmas cujas professoras disseram que "as portas da sala estavam abertas para a pesquisa". Essa fase totalizou 45 horas de observação, com 15 horas em cada turma.

Em ambas as fases, foi utilizado um roteiro de observação, previamente construído; os fatos e impressões dessas vivências foram anotados em um diário de campo. 0 texto do diário continha a "parte descritiva" e a "parte reflexiva" (BOGDAN; BIKLEN, 1994). Na "parte descritiva" foram anotados locais, eventos especiais, atividades, comportamentos dos alunos, conteúdos trabalhados em sala, recursos utilizados, conversas e as formas de interação entre o grupo. Na "parte reflexiva" foram registradas impressões pessoais, encaminhamentos metodológicos, dúvidas, dilemas e conflitos, às vezes fazendo pequenas análises em relação ao que já estava sendo apreendido e interpretado.

Ao lado da observação participante, foram analisados documentos considerados importantes para fundamentar a proposta curricular e sua realização prática. Os principais 
textos analisados foram as Proposições Curriculares da rede, os planejamentos elaborados pelas docentes, as referências que utilizavam para elaborar atividades, os registros no diário de classe, as atividades selecionadas para ensino do conteúdo, o Projeto Político-Pedagógico da escola e o material produzido pela direção e pela coordenação pedagógica direcionado ao professor. Na análise desses documentos, foram considerados seus contextos de produção, distribuição, circulação e as formas de acesso pelos docentes.

Por último, foram realizadas dezoito entrevistas com cinco gestoras e treze professoras. Todas as entrevistas ocorreram na própria escola e a maioria durante o período de aula do turno vespertino. Para entrevistar as professoras, foram utilizados, principalmente, os horários de planejamento, que duram em torno de 50 minutos.

A entrevista semiestruturada possibilitou contato mais direto com as professoras, coordenadoras, diretora, vice e acompanhante pedagógica, permitindo compreender a relação que elas estão estabelecendo com as novas Proposições Curriculares, as reações que manifestam frente à reorganização do currículo, os elementos nos quais se fundamentam para organizar o trabalho docente. 0 roteiro da entrevista foi elaborado a partir das indagações surgidas na análise documental e nas observações e viabilizou a inclusão de outras perguntas no decorrer dos encontros. Todas as entrevistas foram gravadas em áudio, mediante autorização prévia, e em seguida transcritas e submetidas à apreciação das docentes. Os dados da pesquisa foram analisados à luz da análise de conteúdo.

\section{PROPOSIÇÕES CURRICULARES}

\subsection{CONTEXTO DE INFLUÊNCIA}

Para compreender o processo de elaboração das Proposições Curriculares para a rede municipal de Belo Horizonte é necessário, primeiramente, fazer menção ao projeto maior, com base no qual tais proposições foram geradas - a Proposta Escola Plural, implementada em 1995 pela Secretaria Municipal de Educação (SMED). Buscando ressignificar o processo de ensino-aprendizagem, a Escola Plural oficializou em documentos e colocou em prática no interior das escolas um programa baseado em ideias amplamente discutidas por educadores progressistas, como interdisciplinaridade, avaliação processual e formação integral dos estudantes. Essa proposta foi produzida em um contexto de intensa discussão sobre a qualidade da educação em diferentes países do mundo e pode ser considerada como parte de um movimento de renovação pedagógica. 
No entanto, uma pesquisa desenvolvida pelo Grupo de Avaliação e Medidas Educacionais apontou várias dificuldades dos professores em lidarem com a proposta da Escola Plural (DALBEN; BATISTA, 2000). Ao lado disso, os meios de comunicação relacionavam o baixo desempenho dos alunos nas avaliações externas à proposta da Escola Plural. Esses dois fatores se conjugaram levando à produção das Proposições Curriculares. De um lado as queixas constantes dos professores da rede, no sentido de que precisavam de orientações mais claras sobre os conteúdos a serem trabalhados ao longo do ensino fundamental e, de outro, o baixo desempenho da rede nas avaliações sistêmicas.

Ficou acordado no interior da Secretaria de Educação que era necessária a elaboração de diretrizes curriculares, a partir de uma proposta mais aberta, com indicação apenas das capacidades a serem alcançadas. Depois de debates internos, ficou estabelecido que seriam definidas as capacidades por disciplina e por ano de cada ciclo. Tornou-se, então, necessária a legitimação da proposta e, nesse sentido, houve um debate, nos dias 31 de janeiro e 1 de fevereiro de 2007, em um encontro promovido pela SMED, entre educadores da Educação Infantil, Ensino Fundamental e Educação de Jovens e Adultos, no qual foi aprovada a elaboração da proposta curricular.

Por último, é preciso lembrar que o discurso sobre a crise de ineficácia do sistema educacional se inseria/insere em um conjunto de ações implementadas no contexto de reestruturação do Estado brasileiro, o qual vinha/vem definindo suas políticas públicas tendo em vista as recomendações de organizações internacionais, que insistiam/insistem na necessidade de se superar o desencontro entre o sistema educacional e o mercado de trabalho. (COELHO, 2008). Pode-se então situar a elaboração das Proposições Curriculares em um processo de regulação das instâncias administrativas que buscam a qualidade educacional centrando-se em reformas curriculares. Nesse cenário, é preciso indagar se as Proposições Curriculares foram elaboradas para melhorar o desempenho da rede, nos marcos das propostas orientadas por novas formas de gerenciamento e controle, ou de acordo com os ideais de educadores críticos, como foi a proposta da Escola Plural.

\subsection{CONTEXTO DA PRODUÇÃO DO TEXTO POLÍTICO}

Depois de aprovada pelos educadores a ideia de elaboração das Proposições Curriculares, a SMED contratou um grupo de assessores para, juntamente com alguns professores da rede, trabalharem na construção da referida proposta. Foram organizados encontros entre os assessores e os professores da rede para escreverem a primeira versão do documento. Ao final de 2007, a SMED apresentou o texto preliminar “Desafios da Formação: Proposições 
Curriculares - Ensino Fundamental" destinado a orientar o processo de ensino do $1^{\circ}, 2^{\circ}$ e $3^{\circ}$ ciclo. A partir daí foram realizadas discussões entre professores, assessores lespecialistas das diferentes disciplinas), coordenação pedagógica e os representantes da Secretaria Municipal de Educação que acompanhavam as escolas. Esse movimento de debate, denominado pela SMED de "Rede de Formação", teve continuidade em 2008 mobilizando os professores a participarem dos encontros para conhecerem melhor a estrutura da proposta e discuti-la no interior das escolas, de modo a contribuírem na redação do texto final do documento.

Sobre esses encontros, Mariana afirmou que não houve forte mobilização da escola Arco-íris para que os professores participassem do processo de construção do texto. Luiza diz que participou de algumas reuniões, mas não soube se as contribuições da escola fizeram parte do documento final. Por sua vez, uma professora de Arte disse que teve a sensação de tais encontros ocorreram apenas para validar o que já estava pronto.

Conforme pode ser observado pelo depoimento das docentes, da direção e da coordenação, a organização do trabalho na escola favoreceu o envolvimento parcial dos professores na construção do texto. Licenças e faltas de membros da equipe foram razões que impediram a saída de professores para participarem do movimento de construção do currículo, de cursos e de atividades de formação sobre o texto. Também é importante considerar que as docentes necessitariam se ausentar muito da escola para essa participação, gerando uma situação complicada, se for levada em conta a importância da permanência dos professores junto a seus alunos.

0 texto das Proposições Curriculares para o Ensino Fundamental diz que são reafirmados os princípios, ideias, conceitos, práticas e posturas da Escola Plural (BELO HORIZONTE, 2009). Tais princípios refletem a intenção de se construir uma escola inclusiva e democrática, em que organização, a estrutura e o currículo são pensados tendo em vista o combate às práticas pedagógicas que excluem, discriminam e selecionam.

Como havia certa insatisfação com a proposta da Escola Plural, apesar de o documento colocar-se como um desdobramento dessa proposta, os docentes o percebiam como uma ruptura com o que preconizava aquela proposta. Isso mostra que o contexto de produção de texto tem relação estreita com o contexto de influência (BOWE; BALL; GOLD, 1992).

As observações e as entrevistas evidenciaram existir um desencontro entre a intenção do texto e a interpretação de algumas professoras. Durante o período de observação, foi constatado que muitas professoras não relacionavam as Proposições Curriculares à Proposta Escola Plural. Era comum se ouvir expressões como "na época da Escola Plural", "quando era a Escola Plural".

Para a professora Violeta, no movimento de implementação das Proposições Curriculares, foram retomadas práticas pedagógicas vivenciadas nos primeiros anos de sua 
experiência, quando ingressou na rede, no final da década de 1980. A docente observou que naquela época havia na escola supervisoras analisando o planejamento escrito e recuperação de alunos, atividades que, na opinião dela, existiam antes da Escola Plural. Para Violeta, essas atividades estavam sendo retomadas, mesmo que de forma diferente, uma vez que a coordenação pedagógica desempenhava as tarefas da antiga supervisão; passou a haver uma semana de recuperação a cada trimestre com o planejamento sendo feito como antes. No mesmo sentido, para Helena, a elaboração das Proposições Curriculares decretou o fim da Escola Plural.

A falta de compreensão do texto curricular, por parte das professoras, não decorre, muitas vezes, por dificuldades de interpretação, pois, segundo Ball (1994), textos políticos não são necessariamente claros e coesos. Essa falta de clareza faz as professoras compreendê-lo a partir de suas experiências, o que as leva a considerá-lo uma ruptura com a Escola Plural, uma vez que instala na escola práticas mais antigas, como a da supervisão, que passou a ser exercida pela coordenação pedagógica.

As Proposições Curriculares definem capacidades/habilidades a serem desenvolvidas pelos alunos como forma de se adquirir os conhecimentos das disciplinas. 0 termo capacidades/habilidades é empregado "como um norte, uma meta geral de formação que os educadores tomam como referência para a organização e o desenvolvimento das propostas de ensino." (BELO HORIZONTE, 2009, p. 10). A proposta objetivava oferecer um currículo que atendesse às demandas docentes por orientações mais precisas de ensino sem, no entanto, reduzir-se a uma lista de matérias e conteúdos ou a um rol de competências genéricas que, na prática, pouco auxiliam o trabalho dos professores. 0 texto curricular buscava dar espaço para que o professor pudesse definir, tendo em vista o perfil de sua turma e a realidade da escola, o que seria trabalhado em classe.

Ball (1994) discute o movimento incessante que se configura na produção do texto curricular. Essa produção não se encerra quando o texto é publicado, pois o texto curricular é, de alguma forma, sempre reescrito em função da dinâmica, do contexto da prática e dos significados construídos por seus implementadores. Por isso, o contexto de produção de texto não envolve apenas a proposta curricular, mas outros textos que são produzidos em função dessa, bem como textos presentes no ambiente escolar, com os quais a política dialoga.

$\mathrm{Na}$ Escola Arco-íris, circularam textos produzidos interna e externamente, que objetivavam auxiliar o trabalho dos professores e acompanhar suas atividades, segundo o que diziam os gestores e coordenadores pedagógicos. Tais textos buscavam controlar a recepção e a prática curricular. Um deles, denominado "Um elo entre as Proposições Curriculares da Rede e o Planejamento Escolar da Escola Arco-íris", foi elaborado pela equipe da coordenação dos três ciclos, com o objetivo de auxiliar os docentes na tarefa de selecionar e de acompanhar as capacidades a serem trabalhadas a cada trimestre, em cada 
turma. Conforme mostra a Tabela 1, foram descritas as capacidades por disciplina e seus respectivos eixos temáticos, sendo reservado um espaço para as docentes indicarem, por trimestre, a capacidade trabalhada e o nível de abordagem.

Tabela 1 - Fragmento do caderno "Um elo entre as Proposições Curriculares da Rede e o Planejamento Escolar na Escola Arco-íris - $1^{\circ}$ ciclo"

\begin{tabular}{ccccccccccc}
\hline \multicolumn{1}{c}{ Ciências } \\
\hline & 0 planeta onde moro & & & & & & & \\
\hline Anos do ciclo & & $1^{\circ}$ & & $2^{\circ}$ & & $3^{\circ}$ \\
\hline Trimestre & $1^{\circ}$ & $2^{\circ}$ & $3^{\circ}$ & $1^{\circ}$ & $2^{\circ}$ & $3^{\circ}$ & $1^{\circ}$ & $2^{\circ}$ & $3^{\circ}$ \\
\hline $\begin{array}{l}\text { ldentificar alguns ciclos da Natureza no espaço e no tempo } \\
\text { (ciclos da água, dia e noite, estações do ano) }\end{array}$ & $1 / T / C$ & & R/T/C & & T/R/C \\
\hline
\end{tabular}

Fonte: os autores.

Nota: Legenda: (I) introduzir; (T) trabalhar; (C) consolidar; (R) retomar.

Outro texto, este produzido pela SMED, foi a planilha de planejamento trimestral, na qual as professoras descreviam a capacidade, o conteúdo trabalhado, a metodologia, as formas de avaliação e indicavam também o nível de abordagem da referida capacidade, ou seja, se ela seria introduzida, retomada, trabalhada ou consolidada. Essa planilha trouxe muita inquietação ao grupo, fato que será mostrado mais adiante.

Durante o processo de escolha de livros didáticos para o Programa Nacional do Livro Didático 2013, a escola recebeu de uma das coleções uma planilha de planejamento, relacionando as capacidades da disciplina à unidade de conteúdo trabalhada. Segundo a coordenadora, a coleção incluía ainda um CD com atividades próprias para cada capacidade. 0 que se via era o mercado editorial já se mobilizando para ganhar uma fatia do mercado de livro didático, oferecendo justamente o que era considerado ausente no currículo, ou seja, o conteúdo explícito, o que os elaboradores do currículo resistiram em fazer, a referida editora assumiu. Não é preciso dizer que esse material foi bem recebido pelas docentes.

Todo esse material, produzido para auxiliar a leitura e a seleção das capacidades, contribuiu para uma leitura fragmentada e pragmatista do currículo, já que muitas professoras deixaram de realizar uma leitura das concepções teóricas, em busca daquilo que julgaram estar mais relacionado à prática da sala de aula. No entanto, esses textos cumpriram uma das funções do currículo apontadas por Sacristán (2000), que é a de controlar o conteúdo do texto prescrito. 


\subsection{CONTEXTO DA PRÁTICA}

De acordo com Bowe, Ball e Gold (1992), o contexto da prática é onde a politica é interpretada por professores e gestores, tornando-se evidente os limites do controle do Estado sobre a politica e dos autores sobre o texto. Partes do texto serão incompreendidas, modificadas, rejeitadas, destacadas, visto que sua interação com os sujeitos e suas subjetividades, com as condições físicas e materiais da escola e com a dinâmica do cotidiano escolar produzem novos sentidos à política implementada (BOWE; BALL; GOLD, 1992).

A implementação das Proposições, em 2008, ano seguinte à publicação do texto preliminar, coincidiu com a adesão da rede à Provinha Brasil. Também neste ano a prefeitura ou o "Avalia-BH", sistema próprio de avaliação da rede municipal que tinha por objetivo verificar o desempenho acadêmico de todos os alunos matriculados do $3^{\circ}$ ao $9^{\circ}$ ano do Ensino Fundamental, nas disciplinas de Língua Portuguesa, Matemática e, desde 2011, Ciências da Natureza (BELO HORIZONTE, 2012).

A forma como as Proposiç̃̃es Curriculares foram sendo implementadas na escola ganhou contornos que podem ser considerados mais gerenciais com a mudança do cenário político da cidade. Se nos dois primeiros anos de sua existência (2007 e 2008) predominava a discussão do documento e uma adoção fundamentada mais pela conquista e convencimento pedagógico dos professores da rede, do terceiro ano em diante sua adoção passa a ser a condição e a norma para o alcance de metas educacionais. 0 ano de 2009 é marcado pela mudança da gestão administrativa, devido às eleições municipais ocorridas em outubro de 2008, interrompendo os dezesseis anos de gestão do Partido dos Trabalhadores na prefeitura de Belo Horizonte.

A implementação do Programa "BH Metas e Resultados" como plano do novo governo marca o início de uma série de ações e empreendimentos com gerenciamento intensivo e planejamento, focalizando doze áreas de resultados, sendo a Educação uma delas (BELO HORIZONTE, 2012). Através do "Projeto Sustentador Melhoria da Qualidade da Educação", a SMED procurou consolidar a discussão do currículo no interior das escolas. Em função disso, é implantado nas escolas o "Monitoramento e Acompanhamento da Gestão Escolar". 0 Programa de Monitoramento, centrado na figura das professoras acompanhantes pedagógicas e na realização do "Avalia-BH", foi o instrumento utilizado pela SMED para integrar as Proposições Curriculares à cultura pedagógica das escolas.

0 tempo reservado para o estudo das proposições era muito limitado. Na escola, durante os horários das Atividades Coletivas de Planejamento e Avaliação do Trabalho Escolar (ACPATE) e nas reuniões dos professores de um mesmo ano (reunião de agrupamento), e mesmo em casa, como foi observado, as professoras se voltavam para atividades práticas 
relacionadas às atividades de sala de aula. 0 depoimento de Carolina e Violeta evidencia essa preocupação com a prática no contexto do tempo exíguo de que a docente dispõe para lidar com diferentes demandas.

\footnotetext{
E o ruim dessas proposições é que tem muito texto. Vida de professor é muito corrida pra ler tanto texto. Já tem tanta coisa pra ler, pra pesquisar, pra fazer, diários pra elaborar e... São textos importantes? Provavelmente sim... Mas tem que ter algo mais prático na vida dos professores. (Carolina, professora da classe de 8 anos).
}

[...] Na hora que eu li, se não tiver uma pessoa pra te orientar, você fica apavorada. Tanto é que eu não consegui ler todas [as disciplinas]. [...] Que horas que você vai ter tempo pra ler aquilo tudo?! (Violeta, professora da classe de 8 anos) (informações verbais).

As reuniões-prêmio, que ocorriam uma vez por mês e pela qual as professoras recebiam uma ajuda de custo, foram momentos reservados pela Escola Arco-íris para se discutir as Proposições Curriculares. Tratava-se de um momento usado para relacionar as experiências e práticas com o conteúdo do documento, mas o número de professores presentes nesses encontros era ínfimo.

Carolina e Manuela ressaltaram que as Proposições deveriam ter mais exemplos de atividades, recurso que, na opinião das professoras, auxiliaria a prática de ensino. Entretanto, foi observado na pesquisa que essa secundarização das concepções teóricas do texto oficial ocorreu mais pelo anseio por atividades concretas para o trabalho em sala de aula do que pelo não reconhecimento do papel formador de tais concepções.

Quando indagadas sobre os pontos positivos e negativos que viam no texto curricular, as professoras Alessandra, Manuela e Helena destacaram as contribuições de apoio ao trabalho docente. No entanto, Mônica apontou o aspecto homogeneizador desse tipo de currículo ao afirmar que "múltiplas aprendizagens" e "realidades diferentes" na sala de aula, que tornavam difícil seguir um currículo já definido. Na mesma direção, a professora Maria relatou a sensação que tinha de estar "presa" a uma proposta já definida. Esse aspecto homogeneizador das propostas curriculares, que pretendem orientar escolas bem diferentes em sua composição econômica e sociocultural, já foi muito discutido no campo do currículo e fica bem claro no depoimento que se segue:

[...] É como se colocasse todo mundo no mesmo nivel. Nivelasse todo mundo. E nós sabemos que as crianças não estão todas o mesmo nível. Cada um tem a sua especificidade (Ruth, professora da classe de 6 anos). (informação verball. 
Algumas professoras argumentaram que a amplitude das capacidades gerava incompreensões, como fica evidenciado nas seguintes falas:

[...] A minha principal dificuldade com relação às Proposições é a amplitude delas. (Cláudia, professora da classe de 7 anos).

[...] Às vezes, acho que a capacidade é muito ampla, pois ela não tem um conteúdo só. [...] Tem também capacidade que acho que nem tem conteúdo, ela é atitudinal... Então essa é a minha dificuldade. (Camila, professora da classe de 7 anos).

É como eu te falei antes parece que tem algumas [capacidades] que esbarram em outras, confundem. Algumas dão dupla interpretação e confundem. Então fica difíil interpretar o que eles querem realmente. (Manuela, professora da classe de 8 anos).

Quando a gente lê a gente fica angustiada, porque você acha que é muita coisa. Mas depois você começa a ver que tem coisa que você já trabalha. Então, primeiro você fica angustiada, porque é grande mesmo. Aí você pensa que não vai dar tempo, mas acho que com o tempo as coisas vão se esclarecendo. (Cristina, professora da classe de 7 anos) (informações verbais).

Apontaram também que a linguagem técnica, a amplitude e clareza do documento se constituíam em um obstáculo à compreensão plena do mesmo, dificultando o entendimento de algumas capacidades, como pode ser visto nos seguintes depoimentos:

Porque tem algumas palavras que eu acho que são muito específicas mesmo. [..] uma linguagem para quem aprofundou, para quem fez especialização na área da História e da Geografia. [...] Uma capacidade, por exemplo, "perceber a historicidade presente [...]". Assim, a linguagem rebuscada do texto, muitas vezes, te deixa assim... meio sem entender o que que era aquilo [...] (Esmeralda, coordenadora).

Eu acho que devia ser uma coisa mais sintética, entendeu? Tem umas coisas repetitivas nas Proposições. Eu acho que tinha que ser uma coisa mais objetiva. Tem horas que não deixa claro pra você o que você tem que trabalhar, dá margem pra você trabalhar diversas coisas. (Violeta, professora da classe de 8 anos) (informações verbais).

Nas entrevistas algumas professoras disseram que as Proposições Curriculares trabalhavam com uma lógica inversa a que utilizavam, uma vez que na prática partiam dos conteúdos, para depois pensar nas habilidades que estavam sendo formadas. Diferentemente, a nova proposta exigia que, primeiramente, fossem definidas as capacidades/habilidades a 
serem trabalhadas, para então se propor conteúdos e as atividades de ensino. Esse aspecto é destacado nas falas que se seguem:

\begin{abstract}
Na verdade a resistência maior é assim: a sua lógica ldo professorl era uma lógica de conteúdo, você trabalhava com o conteúdo, então ela las Proposições Curriculares] vem inverter a lógica. [...] Ela [Proposições Curriculares] vem nessa lógica invertida Então isso gera um incômodo, te tira do seu lugar! Você estava num lugar de conforto. (Esmeralda, coordenadora).
\end{abstract}

Eu tive dificuldade porque. primeiro eu preparava os conteúdos, depois pensava as capacidades. A diferença agora é que primeiro você escollhe $\circ$ eixo [capacidade] pra depois trabalhar o conteúdo. (Carolina, professora da classe de 8 anos).

Agora está ficando mais dificil porque agora a gente está escolhendo primeiro as capacidades e habilidades. [... A gente seleciona o que a turma está precisando, o que você quer trabalhar com eles, as capacidades e, a partir delas a gente vai procurar as atividades. Então, assim é mais dificil. (Cristina, professora da classe de 7 anos) (informações verbais).

Os conhecimentos adquiridos pelas docentes ao longo de sua história profissional também são mobilizados para a prática pedagógica, e o texto curricular passa, muitas vezes, a ter papel secundário neste contexto. Há práticas que estão nas escolas há muitas décadas e mesmo professoras mais novas lançam mão delas. Ao assistir as aulas, pode ser observado que não foram poucas vezes que as professoras passaram para sua turma atividades do tipo "arme e efetue", "leia e responda as questões", "copie a ficha" etc.

Nos primeiros anos de existência da Escola Arco-íris, os projetos de trabalho formaram a base de suas práticas pedagógicas. Segundo os relatos de docentes mais antigos, esses projetos eram organizados coletivamente e pautavam a ação do corpo docente. A partir das discussões comuns, cada professor organizava sua prática em sala de aula, não havendo obrigação de apresentar um plano de aula para a coordenação ou direção. Essa prática se modifica, a partir da nova proposta curricular, quando os coordenadores pedagógicos passaram a cobrar um planejamento trimestral, que devia ser elaborado e apresentado à coordenação e direção, mudando assim radicalmente a lógica adotada até então pela escola.

Para esse planejamento trimestral era utilizado um modelo elaborado pela equipe da SMED, a já referida "planilha", cujo objetivo era garantir a implementação das Proposições Curriculares. Nas planilhas, as professoras descreviam, por disciplina, a capacidade, o conteúdo trabalhado, a metodologia e as formas de avaliação, além de indicarem se a capacidade seria 
introduzida, retomada, trabalhada ou consolidada. 0 Quadro 1 mostra a parte central da planilha:

Quadro 1 - Fragmento da planilha de planejamento trimestral

\begin{tabular}{|l|l|l|l|l|l|}
\hline $\begin{array}{l}\text { Capacidade/ } \\
\text { Habilidade }\end{array}$ & $\begin{array}{l}\text { Descrição da capacidade/ } \\
\text { habilidade }\end{array}$ & $\begin{array}{l}\text { Forma de } \\
\text { abordagem } \\
(\mathrm{l}, \mathrm{R}, \mathrm{T}, \mathrm{C})\end{array}$ & $\begin{array}{l}\text { Conteúdo } \\
\text { trabalhado }\end{array}$ & $\begin{array}{l}\text { Metodologia utilizada } \\
\text { para o desenvolvimento } \\
\text { da capacidade }\end{array}$ & $\begin{array}{l}\text { Forma de } \\
\text { avaliação }\end{array}$ \\
\hline
\end{tabular}

Fonte: os autores.

Nota: Legenda: (I) introduzir; (T) trabalhar; (C) consolidar; (R) retomar

A proposta deste modelo de planejamento causou certo incômodo ao professorado. Para alguns a planilha significava uma forma de controle, um trabalho a mais, uma afronta à autonomia docente em sala de aula, conforme pode ser visto a seguir:

No primeiro momento foi de stress mesmo, todo mundo estressado, ansioso, com medo de estar fazendo errado, porque não estava acostumado. Há muito tempo não se exige um planejamento numa formatação padrão. № ano passado o professor fazia o planejamento e entregava ao coordenador, mas a coordenação não deu conta de fazer as intervenções necessárias. (Esmeralda, coordenadora).

A gente percebe dificuldade [...] Parece que as professoras pensam assim: "Estão fiscalizando o meu trabalho!" "Eu tenho que colocar aqui tudo que eu falo dentro da minha sala". "Eu não quero isso, eu estou perdendo a minha liberdade, a minha autonomia na minha sala!" "Eu tenho que fazer o que está aqui" (Gabriela, coordenadora).

[...] A professora faz o planejamento e quando você pega uma avaliação dela, a avaliação que ela fez não tem nada a ver com aquelas capacidades que ela colocou. Então, quer dizer: ela está planejando, porque alguém está cobrando, porque a direção está cobrando, porque coordenação está cobrando, porque a gerência vai cobrar. (Bita, acompanhante pedagógica)

Pra mim, por exemplo, eu sei trabalhar na sala, mas o registro das coisas é mais complicado. (Violeta, professora da classe de 8 anos) (informaç̃̃es verbais).

Nas falas das professoras em diferentes situações foi observada uma insegurança em decidirem por si mesmas o conteúdo a ser trabalhado em sala de aula e um medo de estarem fazendo escolhas equivocadas, o que levava a maioria a recorrer aos livros didáticos e a consultar a coordenadora pedagógica. Contreras (2002) relaciona essa postura "dependente" com o processo de racionalização do ensino, que separa quem planeja de quem 
executa, indicando a "perda de autonomia dos professores na realização do seu trabalho profissional." (CONTRERAS, 2002, p. 38).

A pouca participação dos docentes nos macro-contextos que debatem e planejam a educação tem seus efeitos nos micro-contextos e parece instaurar uma contradição. $\mathrm{Na}$ sala de aula, o que se espera são educadores criativos capazes de construir um processo de ensino-aprendizagem mais crítico, democrático e significativo, conforme se defende em discursos acadêmicos e nos discursos das políticas curriculares. Esta pesquisa mostrou que essa contradição está presente nas ações da Secretaria Municipal de Educação, como evidencia a seguinte fala:

\footnotetext{
[...] É como se a SMED, nesse momento, percebesse que tem um grupo de professores na rede que dá conta de pensar a prática, de avançar. Pegou grande parte destes professores pra gerências, pra acompanhar, pra trabalhar na própria SMED. E como se a SMED acreditasse que tem um outro grupo de professores só pra executar e obedecer, que não dá conta de pensar a prática. Mas ai eles querem que esse professor tenha uma prática atualizada. (Ana, diretora) (informação verbal).
}

Desse modo, a própria Secretaria estaria fortalecendo uma divisão de trabalho, na medida em que colocava nos órgãos gestores centrais as professoras mais experientes, atribuindo-lhes a função de "supervisionar" o trabalho docente, como ocorria com as acompanhantes pedagógicas que as regionais enviavam para as escolas. Essa divisão de trabalho restringe a autonomia docente, como salienta Contreras (2002), pois coloca o professor como mero executor de atividades cujos objetivos foram pensados por outros.

A coordenação pedagógica observou que em muitas situações o planejamento era feito apenas para mostrar o cumprimento de uma tarefa, já que as professoras deveriam entregá-lo para a sua equipe. De acordo com a opinião das coordenadoras, o professor fazia seu trabalho, muitas vezes, sem nenhuma ligação com o planejamento apresentado. Evidência disso foi observado nas ACPATE, que se destinava ao planejamento das aulas. Nesses horários as professoras dedicavam considerável tempo procurando nos livros didáticos ou na internet por atividades para trabalhar os conteúdos em sala de aula, sem demonstrarem preocupações com o planejamento que haviam feito.

Construir novas formas de avaliação estava também na pauta de discussão da escola - como avaliar as capacidades? Esta era uma pergunta cuja resposta o grupo estava tentando construir, buscando inclusive superar a forma mais legitimada de avaliação nas instituições escolares, ou seja, a prova escrita, que por vezes era elaborada segundo o modelo das avaliações externas. 
As coordenadoras pedagógicas afirmaram que as práticas avaliativas de algumas professoras se pautavam no "treinamento" dos alunos para fazer as avaliações externas, deixando de aferir outras capacidades que tais avaliações não contemplavam/contemplam e que não são necessariamente avaliadas com provas escritas. Havia, por exemplo, uma preocupação das docentes em trabalharem com questões de múltipla escolha, para melhorar o desempenho dos alunos nas avaliações externas.

Um episódio em que também ficou bem clara essa preocupação das docentes com as avaliações externas ocorreu em uma reunião entre professoras do $1^{\circ}$ e $2^{\circ}$ ano do $1^{\circ}$ ciclo, classes de 6 e 7 anos, respectivamente. As docentes debatiam o ensino da letra cursiva que, na opinião delas, não deveria ser introduzido imediatamente no $1^{\circ}$ ano do ciclo, pois exigia um trabalho de mais longo prazo. No entanto, argumentaram que letra cursiva, por ser cobrada nas avaliações externas, seria trabalhada desde o primeiro ano.

Segundo a diretora da escola, a SMED que antes encaminhava o trabalho mais sintonizada com as propostas da Escola Plural, terminou orientando suas práticas em consonância com as demandas das avalições externas e das concepções a elas subjacentes.

[...] A SMED está dividida entre essa política que aí que eu não sei analisar, se é neoliberalismo ou o que que é. Essa política de metas onde eu tenho que cumprir metas, meta pra lá, meta pra cá... E aí vem essas avaliações externas como uma maneira de medir se a meta foi alcançada. (Ana, diretora) (informação verbal).

A denominada cultura da avaliação passou a invadir as escolas, desde que foram introduzidas as avaliações externas. Essas avaliações passaram a definir os currículos e as escolas e, mais especificamente, os professores também passaram a ser cobrados, no sentido de melhoria do desempenho dos alunos nesses testes. Diante dessa pressão por melhores resultados, as professoras, muitas vezes, deixam de lado atividades que não serão avaliadas pelos testes nacionais e locais para "treinarem" alunos naquilo que é mais solicitado nos testes (SANTOS, 2013).

As Proposições Curriculares e os instrumentos de controle que a acompanharam exigia um tempo de estudo e de trabalho que o professor não dispunha. 0 tempo de planejamento e organização das atividades nas cinco horas de ACPATE que o professor tinha durante a semana não eram suficientes, pois incluíam a resolução de outras demandas previsíveis e imprevisíveis do dia-a-dia escolar, como receber pais, resolver questões disciplinares ou conflitos entre os alunos, corrigir cadernos, exercícios, provas, etc., fazendo com que as docentes tivessem que levar muitas tarefas para casa. Exemplo disso foi a fala da professora Helena que relatou que estava cozinhando e queimou o alimento que preparava por causa 
do preenchimento da planilha. É que para atender o prazo solicitado pela acompanhante pedagógica para o envio da planilha e para conseguir dar conta das atividades domésticas realizava as duas coisas ao mesmo tempo.

Novas cobranças eram/são feitas ao professor que se deparava/depara com inúmeras imposições, tarefas e situações para resolver, como participar da gestão da escola, fazer planejamentos trimestrais, melhorar o desempenho dos alunos nos testes, entre outras. 0 acúmulo de trabalho levava/leva as docentes a se sentirem cansados e desgastados, sobretudo, em um contexto em que tem de lidar com uma série de problemas, como por exemplo, a indisciplina dos alunos. Essa intensificação do trabalho docente já vem sendo discutida em vários trabalhos nas últimas décadas (APPLE, 2005; OLIVEIRA, 2003; FELDFEBER, 2007; HYPOLITO; VIEIRA; PIZZI, 2009).

No contexto de intensificação do trabalho docente, as professoras da Escola Arco-íris, buscaram formas para ajudá-las a atenderem as demandas postas pela escola. As docentes, por exemplo, utilizam algumas estratégias para facilitar o trabalho de apresentar as planilhas à coordenação, tais como aderir a um planejamento já pronto ou dividir o planejamento com as colegas do mesmo ano, deixando que cada uma trabalhasse com uma disciplina e depois socializasse o seu trabalho com as demais colegas.

Ball (2002) discute as repercussões das reformas educacionais, nesse caso a introdução de um novo currículo, na subjetividade dos docentes. As demandas postas por uma nova proposta podem provocar diferentes sentimentos negativos no professorado. Algumas vezes nos espaços de formação os professores demonstraram sentimentos de angústia (quando não sabiam mais o que fazer para o aluno aprender), ansiedade (quando se preocupam em avançar na matéria em função das provas sistêmicas, inibindo a participação mais ativa dos alunos) e desconforto (quando iam para a formação e "descobriam" que precisavam aprender muitas coisas).

0 contexto da prática mostrou que, mesmo com todos os mecanismos para controlar a recepção do currículo pelos órgãos gestores, os professores ressignificavam a proposta curricular de acordo com diferentes fatores. A forma como os docentes trabalhavam antes da introdução do novo currículo, as experiências ao longo de sua vida profissional, o clima da escola e as exigências postas pelo trabalho cotidiano são elementos fundamentais na prática de sala de aula. Como argumentam Ball, Maguire e Braun (2012), os currículos não são implementados, eles são recriados pelo professor em sala de aula. 


\section{CONSIDERAÇÕES FINAIS}

A tensão entre homogeneização e heterogeneização do currículo, entre autonomia e controle do trabalho docente, entre o currículo prescrito e o currículo em ação ficaram evidenciadas nas mudanças ocorridas na rede municipal de educação de Belo Horizonte, desde a proposta da Escola Plural até a elaboração e implementação das Proposições Curriculares. Em síntese, a pesquisa mostrou que:

a. em uma rede com tradição em elaboração do currículo pela escola houve dificuldade em trabalhar com um único currículo para toda a rede;

b. mesmo utilizando variadas formas de controle dos significados do currículo, o que foi trabalhado em classe, geralmente, teve mais relação, entre outros fatores, com as tradições consolidadas na prática pedagógica;

c. a implementação do currículo foi um processo que acarretou intensificação do trabalho pelas novas exigências e demandas postas ao cotidiano dos docentes;

d. as docentes, muitas vezes, não colocavam em prática o que preconizava a proposta, tanto por dificuldades em relação ao texto, como pelas exigências postas à prática pelas avaliações externas;

e. o currículo prescrito, de um lado, e o currículo em ação, de outro, podem evidenciar uma divisão de trabalho entre planejadores e executores, reduzindo a autonomia do professor;

f. os esforços, tempo e dinheiro gasto para controlar a implementação do currículo poderiam ser melhor aproveitados na realização dos currículos nas escolas, como há anos defende a literatura no campo do currículo.

Os elementos listados acima podem servir como ponto de partida para se pensar o processo de implementação das BNCC. É importante considerar que todas as dificuldades relatadas ocorreram em uma escola com boa infraestrutura, em que quase a totalidade das docentes tinha graduação em Pedagogia obtida em cursos presenciais, em um município em que a Secretaria de Educação costumava ter uma tabela de salários bem acima daquela paga pelo Estado de Minas Gerais e por outras capitais.

Há que se considerar que as Proposições Curriculares prescreveram novas orientações para o trabalho docente em um contexto em que se discutia o papel do currículo 
no tratamento da diferença, da diversidade e da subjetividade, mas também em um cenário em que se definia o que constitui a escola eficaz a partir dos índices de desempenho. Nesse sentido, no próprio texto das Proposições, na parte introdutória, buscou mostrar suas conexões com a proposta que a antecedeu (Escola Plural), ou seja, o texto deixava claro sua adesão às teorias críticas do currículo. No entanto, com o passar do tempo e as cobranças em termos de melhoria do desempenho nas avalições externas levaram, tanto a escola como a Secretaria de Educação, a buscarem formas de controle do currículo por meio das planilhas de planejamento e das reuniões internas e externas à escola. Isso mostra que o ideário preconizado pelos trabalhos sobre a escola eficaz começou a ter penetração na rede que, ancorada no passado, na concepção da educação como processo de formação humana, passou a ser influenciada por ideias economicistas da educação, cuja centralidade está na formação de mão de obra, objetivando o aumento da competitividade do país. Atualmente, em tempos de pandemia, fica claro que valores como a solidariedade, empatia pelo outro, consciência social são muito importantes, embora não sejam avaliados nos testes nacionais e internacionais.

A BNCC foi pensada e elaborada em um contexto em que a padronização do ensino é decorrente desse receituário economicista, fazendo parte de um ideário compartilhado por empresários e educadores que se guiam por concepções mercadológicas e mercantis da educação. Essa visão estreita da educação, cujos efeitos já foram bem mostrados pela literatura crítica e pós-crítica de currículo, tem sérias implicações na vida social e na consolidação de valores democráticos. Agora, no momento da crise como a que vivemos, essa visão reducionista revela mais agudamente toda sua inadequação e equívocos da proposta da BNCC. A educação que precisamos não pressupõe currículos nacionais. A educação que atenda à realidade do tempo presente pressupõe e aponta para currículos que possam garantir a autonomia das escolas e dos professores, acolhendo a diversidade social e cultural que nos rodeia, orientada por valores que permitam a construção de uma sociedade melhor e mais justa do que essa em que vivemos.

\section{REFERÊNCIAS}

ANDRÉ, M. E. D. A. Estudo de caso em Pesquisa e Avaliação Educacional. Brasília, DF: Líber Livro Editora, 2005. 70 p. (Série Pesquisa, v. 13).

APPLE, M. A política do conhecimento oficial: faz sentido a ideia de um currículo nacional? In: MOREIRA, A. F. B.; SILVA, T. T. da (org.). Currículo, Cultura e Sociedade. 9. ed. Tradução: Maria Aparecida Baptista. São Paulo: Cortez, 2005. p. 59-91.

BALL, S. J.; MAGUIRE, M.; BRAUN, A. How schools do policy: policy enactments in secondary schools. London: Routledge; Taylor and Francis Group, 2012. 
BALL, S. J. Educational reform: a critical and post-structural approach. Buckingham: Open University Press, 1994. $164 \mathrm{p}$.

BALL, S. J. Reformar escolas/reformar professores e os terrores da performatividade. Revista Portuguesa de Educação, v. 15, n. 2, p. 3-23, 2002.

BELO HORIZONTE. Secretaria Municipal de Educação. Avalia BH: Rede Municipal de Educação. Belo Horizonte: [s. n.], 2012. 136 p.

BELO HORIZONTE. Secretaria Municipal de Educação. Desafios da formação: proposições curriculares para o Ensino Fundamental. Textos introdutórios. Belo Horizonte: [s. n., 2009. 53 p.

BOGDAN, R. C.; BIKLEN, S. K. Investigação qualitativa em Educação: uma Introdução à teoria e aos métodos. Tradução: Maria João Alvarez, Sara Bahia dos Santos e Telmo Mourinho Batista. Porto: Porto Editora, 1994. 336 p.

BOWE, R.; BALL, S.; GOLD, A. Reforming education \& changing schools: case studies in policy sociology. London: Routledge, 1992. $192 \mathrm{p}$.

COELHO, M. I. M. Vinte anos de avaliação da educação Básica no Brasil: aprendizagens e desafios. Ensaio: avaliação e políticas públicas em Educação, Rio de Janeiro, v. 16, n. 59, abr./jun. 2008. p. 229258.

CONTRERAS, J. A autonomia de professores. São Paulo: Cortez, 2002.

DALBEN, A. I. L. de F.; BATISTA, J. R. Avaliação da implementação do projeto político-pedagógico Escola Plural. Belo Horizonte: UFMG/FAE/GAME, 2000. 141 p.

FELDFEBER, M. La regulación de la formación y el trabajo docente: un análisis critico de la "agenda educative" en América Latina. Educação \& Sociedade, v. 28, n. 99, p. 444-465, 2007.

GOODSON, I. Currículo: teoria e história. Tradução: Att́lio Brunetta. 11 ed. Petrópolis, RJ: Vozes, 2011.

HYPÓLITO, A. M.; VIEIRA; J. S.; PIZZI, L. C. V. Reestruturação Curricular e auto-intensificação do trabalho docente. Currículo sem Fronteiras, v. 9, n. 2, p. 100-112, jul./dez. 2009. Disponível em: http://www. curriculosemfronteiras.org/vol9iss2articles/hypolito-vieira-pizzi.pdf. Acesso em: 15 abr. 2020.

LOPES, A. C. Relações macro-micro na pesquisa em currículo. Cadernos de Pesquisa, v. 36, n. 129, p. 619-635, set./dez. 2006. Disponível em: http://www.scielo.br/pdf/cp/v36n129/a0636129.pdf. Acesso em: 15 mar. 2020.

MACED0, E. Currículo: política, cultura e poder. Currículo sem Fronteiras, v. 6, n. 2, p. 98-113, jul./dez. 2006. Disponivel em: http://www.curriculosemfronteiras.org/vol6iss2articles/macedo.pdf. Acesso em: 10 mar. 2020. 
MAINARDES, J. Abordagem do ciclo de políticas: uma contribuição para a análise de políticas educacionais. Educação \& Sociedade, v. 27, n. 94, p. 47-69, jan./abr. 2006. Disponível em: http://www.scielo.

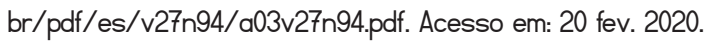

OLIVEIRA, D. A. As reformas educacionais e suas repercussões sobre o trabalho docente. In: OLIVEIRA, D. A. (org.) Reformas educacionais na América Latina e os trabalhadores docentes. Belo Horizonte: Autêntica, 2003. p. 13-35.

SACRISTÁN, J. G. 0 currículo: uma reflexão sobre a prática. 3. ed. Tradução: Ernani F. da R. Rosa. Porto Alegre: Artmed, 2000. 352 p.

SANTOS, L. L. A avaliação em debate. In: BAUER, A.; GATTI, B. A. (org.). Vinte e cinco anos de avaliação de sistemas educacionais no Brasil: implicações nas redes de ensino, no currículo e na formação de professores. 1. ed. Florianópolis: Fundação Carlos Chagas/Ed. Insular, 2013. v. 2, p. 229-245.

SILVA, T. T. Currículo e Identidade social: territórios contestados. In: SILVA, T. T. (org.). Alienígenas na sala de aula. 8. ed. Petrópolis: Vozes, 2009. p. 190-207. (Coleção Estudos Culturais em Educação).

SILVA, T. T. Documentos de identidade: uma introdução às teorias do currículo. 2. ed. Belo Horizonte: Autêntica, 2005. 154 p.

Endereço para correspondência: Avenida Presidente Antônio Carlos, 6627, Pampulha, Belo Horizonte, Minas Gerais, Brasil; luciolaufmg@yahoo.com.br 